\title{
Molecular signalling in hepatocellular carcinoma: Role of and crosstalk among Wnt/ $\beta$-catenin, Sonic Hedgehog, Notch and Dickkopf-1
}

\author{
Alexandros Giakoustidis MD PhD ${ }^{1,2}$, Dimitrios Giakoustidis MD PhD ${ }^{3}$, Satvinder Mudan MD FRCS $1,4,5$, \\ Argyrios Sklavos MD MSc ${ }^{3}$, Roger Williams CBE MD FRCP ${ }^{1}$
}

\begin{abstract}
A Giakoustidis, D Giakoustidis, S Mudan, A Sklavos, R Williams. Molecular signalling in hepatocellular carcinoma: Role of and crosstalk among WNT/ $\beta$-catenin, Sonic Hedgehog, Notch and Dickkopf-1. Can J Gastroenterol Hepatol 2015;29(4):209-217.
\end{abstract}

Hepatocellular carcinoma is the sixth most common cancer worldwide. In the majority of cases, there is evidence of existing chronic liver disease from a variety of causes including viral hepatitis B and C, alcoholic liver disease and nonalcoholic steatohepatitis. Identification of the signalling pathways used by hepatocellular carcinoma cells to proliferate, invade or metastasize is of paramount importance in the discovery and implementation of successfully targeted therapies. Activation of Wnt/ $\beta$-catenin, Notch and Hedgehog pathways play a critical role in regulating liver cell proliferation during development and in controlling crucial functions of the adult liver in the initiation and progression of human cancers. $\beta$-catenin was identified as a protein interacting with the cell adhesion molecule E-cadherin at the cell-cell junction, and has been shown to be one of the most important mediators of the Wnt signalling pathway in tumourigenesis. Investigations into the role of Dikkopf- 1 in hepatocellular carcinoma have demonstrated controversial results, with a decreased expression of Dickkopf-1 and soluble frizzled-related protein in various cancers on one hand, and as a possible negative prognostic indicator of hepatocellular carcinoma on the other. In the present review, the authors focus on the Wnt/ $/$-catenin, Notch and Sonic Hedgehog pathways, and their interaction with Dikkopf-1 in hepatocellular carcinoma.

Key words: $\beta$-catenin; Dickkopf-1; Hepatocellular carcinoma; Notch; Sonic Hedgehog; Wnt

\section{MOLECULAR SIGNALLING IN HEPATOCELLULAR CARCINOMA}

In the majority of cases of hepatocellular carcinomas (HCCs), there is evidence of existing chronic liver disease as a predisposing factor $(1,2)$. Almost all pathological liver conditions encompassing fibrosis and cirrhosis have been shown to lead with the development of HCC, including chronic viral hepatitis B and C, alcoholic liver disease, metabolic liver disease, nonalcoholic steatohepatitis, primary biliary cirrhosis and primary sclerosing cholangitis (3). As a consequence of hepatocyte injury, and in response to released inflammatory cytokines and oxidative stress, stellate cells and portal fibroblasts undergo activation and myofibroblastic transformation, leading to the development of fibrosis and, eventually, cirrhosis (4). Hepatocytes proliferate to regenerate the injured liver, albeit in states of continuing inflammation and oxidative stress, and in the presence of inciting agents capable of direct or indirect genotoxic damage.
La signalisation moléculaire en cas de carcinome hépatocellulaire : le rôle et la diaphonie entre les voies Wnt/ß-caténine, Sonic Hedgehog, Notch et la protéine Dickkopf-1

Le carcinome hépatocellulaire est le sixième cancer en importance de par le monde. Dans la majorité des cas, il y a des manifestations de maladie hépatique chronique attribuable à divers facteurs, y compris les hépatites $\mathrm{B}$ et $\mathrm{C}$ virales, les maladies hépatiques d'origine alcoolique et la stéatohépatite non alcoolique. La détermination des voies de signalisation utilisées par les cellules des carcinomes hépatocellulaires pour proliférer, envahir ou métastaser est d'une importance capitale pour découvrir et mettre en œuvre des thérapies bien ciblées. L'activation des voies Wnt/ $\beta$-caténine, Notch et Hedgehog jouent un rôle essentiel pour réguler de la prolifération des cellules hépatiques pendant l'évolution du cancer et pour contrôler des fonctions cruciales du foie adulte lors de l'initiation et de l'évolution des cancers humains. Il a été établi que la $\beta$-caténine est une protéine qui interagit avec la molécule d'adhésion cellulaire E-cadhérine à la jonction intercellulaire et qu'elle est l'un des principaux médiateurs des voies de signalisation Wnt dans la tumorigenèse. Les recherches sur le rôle de la protéine Dikkopf-1 dans les carcinomes hépatocellulaires ont donné des résultats controversés, avec une diminution de l'expression de la protéine Dickkopf-1 et de la protéine soluble rapidement fermentescible dans divers cancers d'une part, et un indicateur pronostique de carcinome hépatocellulaire au potentiel négatif d'autre part. Dans la présente analyse, les auteurs s'attardent sur les voies Wnt/ $\beta$-caténine, Notch et Sonic Hedgehog et sur leurs interactions avec la protéine Dikkopf-1 en présence d'un carcinome hépatocellulaire.

\footnotetext{
${ }^{1}$ Institute of Hepatology, Foundation for Liver Research; ${ }^{2}$ Department of Surgery, The London Clinic, London, United Kingdom; ${ }^{3}$ Division of

Transplantation, Department of Surgery, School of Health Sciences, Aristotle University of Thessaloniki, Hippokration General Hospital, Thessaloniki,

Greece; ${ }^{4}$ Department of Surgery, The Royal Marsden NHS Trust; ${ }^{5}$ Department of Surgery and Cancer, Faculty of Medicine, Imperial College London, London, United Kingdom
}

Correspondence: Dr Alexandros Giakoustidis, 116 Harley Street, London W1G 7JL, United Kingdom.

Telephonelfax 44(0)20-7935-3690, e-mail alexgiakoustidis@gmail.com

Received for publication November 28, 2014. Accepted December 13, 2014 


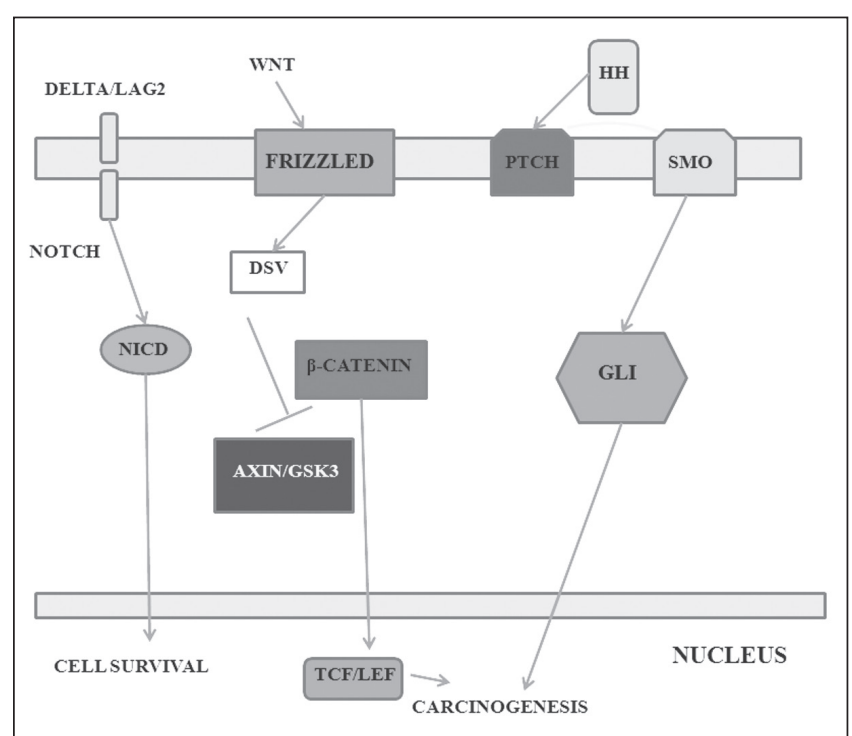

Figure 1) Overview of Wnt/ $\beta$-catenin, Hedgehog (HH) and Notch mode of action. DSV Dishevelled; GLI Glioblastoma transcription factors; GSK-3 $\beta$ Glycogen synthase kinase $3 \beta$, LEF Lymphoid-enhancer factor; NICD Notch intracellular domain; PTCH Patched; SMO Smoothened; TCF T-cell factor

action, possible interaction, crosstalk or overlap can not be excluded. A simplified overview of $\mathrm{Wnt} / \mathrm{\beta}$-catenin, $\mathrm{Hh}$ and Notch mode of action is presented in Figure 1 and explained in more detail below.

In the current review, we have focused on the important features of the Wnt pathway, especially in its canonical form and in relation to the activation of $\beta$-catenin, which appears to be among the main alterations of molecular signalling in HCC. Additionally, we consider the role of Dikkopf-1 in HCC and the controversial results reported, with experimental studies indicating a beneficial role, whereas recent clinical reports have highlighted its possible negative prognostic significance. Finally, we explore the Hh and Notch signalling pathways, their implication in hepatocarcinogenesis and possible interactions with Wnt/ß-catenin.

\section{THE WNT PATHWAY}

Wnt, a signalling pathway found in all species, was first identified in the fruit fly Drosophila melanogaster as the product of the Wingless gene $(w g)$, mutations in which led to the frequent loss of the wing (11). Nusse and Varmus (12) found that insertion of the mouse mammary tumour virus at the int1 locus of Wnt in the mouse genome turned on the proto-oncogene and led to tumour formation, leading to the first member of the Wnt pathway being called Wnt-1. Wnt genes encode a large family of secreted glycoproteins that act as extracellular signalling molecules and result in activation of $\beta$-catenin. $\beta$-catenin is generally identified in three distinct loci: at cellular adherent junctions, where it directly interacts with E-cadherin; in the cytosolic space; and in the nucleus. In most normal unstimulated adult cells, the Wnt/ $\beta$ catenin pathway is inactive, and this is ensured by the absence of Wnt protein and the degradation of $\beta$-catenin. In the absence of activated Wnt $/ \beta$-catenin signalling, cytosolic $\beta$-catenin is phosphorylated by the core proteins axin, adenomatous polyposis coli (APC), glycogen synthase kinase 3 (GSK3) and casein kinase 1 (13).

The $\beta$-catenin protein is encoded by CTNNB1; mutations of this gene, which is the downstream effector of the $\mathrm{Wnt} / \beta$-catenin pathway, have been observed in cases of HCC $(14,15)$, as well as increased $\beta$-catenin activation (16-18). The $\mathrm{Wnt} / \beta$-catenin pathway, which has been intensely studied in prenatal development and liver organogenesis (19), is a critical regulator of liver development and plays an important role in many aspects of postnatal liver homeostasis. Associated with many important functions of the liver, such as ammonia and nitrogen metabolism, and bile acid homeostasis, it helps in the recovery from metabolic injury and oxidative stress. The $\mathrm{Wnt} / \beta$-catenin controls tissue development in embryos and tissue maintenance in adults in cell proliferation, epithelial-mesenchymal transitions and cell death. Activation of the Wnt pathway leads to uncontrolled cell proliferation and growth, promoting the development of multiple types of cancer $(20,21)$.

Activation of the Wnt pathway is through the binding of secreted growth factors of the Wnt family to Frizzled $(\mathrm{Fz})$ receptors at the surface of target cells. Intracellular signalling of Wnt ligands uses two different signal transduction pathways, the 'canonical pathway', which involves regulation of the protein $\beta$-catenin, and the 'noncanonical pathway', which is independent of $\beta$-catenin. Although the two Wnt pathways have been studied separately, there is evidence indicating cross-talk between the two pathways. Upregulation of Wnt ligand expression, increased expression of the $\mathrm{Fz}$ receptors, methylation of secreted Fz-related proteins (sFRPs), mutations in axin1 and tyrosine-phosphorylation-dependent activation of $\beta$-catenin are responsible for activation of $\beta$-catenin $(22,23)$. In HCC induced by hepatitis B virus, canonical Wnt3 and downstream $\beta$-catenin target genes were upregulated. This upregulation of the Wnt pathway by Wnt3 was mediated by $\mathrm{Fz}-7$ receptor (FZD7), and activation of the Wnt pathway in a Wnt3-overexpressing cell line was abolished by small interfering RNA-mediated FZD7 knockdown (24).

Canonical Wnt signalling is more frequently activated in welldifferentiated HCC cells, while noncanonical Wnt signalling is more frequently activated in poorly differentiated HCC. Expression of the noncanonical Wnt5a, which is known to inhibit canonical Wnt signalling, was increased in poorly differentiated HCC cell lines (25). When Wnt5a is expressed in a well-differentiated cell line that normally shows high canonical Wnt activation due to an activating $\beta$-catenin mutation, repression of canonical Wnt signalling is found. Combining the upregulation of $\mathrm{Wnt} 3$ in canonical pathway and Wnt5a in the noncanonical pathway, we can assume that the two Wnt pathways are selectively activated or repressed based on the differentiation status of HCC cells, and have complementary roles in the hepatocarcinogenesis. Canonical Wnt signalling contributes to tumour initiation and noncanonical Wnt signalling to tumour progression (26). In addition to Wnt5a, the noncanonical Wnt11 was recently found to have a role as a cancer suppressor, providing further proof of a complex interplay between the canonical and noncanonical Wnt signalling pathways. Expression levels of Wnt11 were lower in human HCC tumors compared with adjacent liver tissue, and overexpression of Wnt11 reduced cell motility and migration of liver cancer cell lines via activation of Rho kinase (27).

\section{CANONICAL WNT SIGNALLING AND $\beta$-CATENIN ACTIVATION PATHWAY}

As already referred to, the Wnt genes encode a large family of secreted glycoproteins that act as extracellular signalling molecules, initiating a signalling cascade, which results in activation of $\beta$-catenin. In canonical Wnt signalling, $\beta$-catenin plays the key role in transduction signalling. Its concentration in the cytoplasm of unstimulated cells is kept very low through phosphorylation by two kinases, casein kinase 1 and GSK3 $\beta$, functioning in a multiprotein complex including the products of two tumour suppressor genes, the APC and AXIN genes. Phosphorylated $\beta$-catenin is then ubiquitinylated, resulting in its proteasomal degradation. Accessibility of the Wnt ligands to the FZ receptors is controlled by different Wnt inhibitors present in the extracellular compartment that prevent illegitimate $\beta$-catenin transduction signalling. In the activation state, when Wnt ligands bind to FZ-lowdensity lipoprotein receptor-related protein 5/6 (FZ-LRP5/6) receptor complexes, a series of events preventing the cytosolic degradation of $\beta$-catenin occurs, inducing $\beta$-catenin accumulation. The complex formed by Wnt-FZ-LRP5/6 is followed by recruitment of the scaffolding protein Dishevelled, phosphorylation of LRP6 and recruitment of 
the axin degradation complex, preventing phosphorylation of $\beta$-catenin, its stabilization and cytoplasmic accumulation. The subsequent translocation of $\beta$-catenin to the nucleus and formation of a complex with the T-cell factor/lymphoid-enhancer factor (TCF/LEF) transcription factors activates target gene expression (Figure 2). A potential crosstalk among various liver cells expressing different Wnt ligands is highly possible and lipoprotein particles and glypicans can act as vehicles for the movement of Wnt ligands to distant sites, suggesting that intracellular Wnt signalling can be modulated by systemic signals $(28,29)$.

\section{$\beta$-CATENIN MUTATION ACTIVATION IN HCC}

The mechanism of $\beta$-catenin activation in $\mathrm{HCC}$ is due to mutations in the $\beta$-catenin gene (CTNNB1), which have been noted in approximately $20 \%$ to $40 \%$ of all cases (30-35). Mutations have also been reported in the components of the degradation complex of $\beta$-catenin including axin 1 in approximately $3 \%$ to $16 \%(30,35-37)$ and axin2 in approximately $3 \%$ of all HCC cases (37).

These proteins form an $\alpha$-catenin 'degradation complex,' allowing in this way the phosphorylated $\beta$-catenin to be recognized by $\beta-\operatorname{Tr} C P$, targeted for ubiquitination, and degraded by the proteasome $(38,39)$. In the absence of the Wnt signal, TCF would act as a repressor of Wnt target genes by binding their promoter and enhancer regions, with sequence specificity and preventing their expression; when in the presence of Wnt signalling, the $\beta$-catenin degradation process is disrupted and it accumulates in the cytoplasm and translocates to the nucleus. In the nucleus, $\beta$-catenin binds to TCF homologues and LEF, resulting in alteration of the transcriptional machinery, removing the repression and activation of the target genes. Nuclear levels of $\beta$-catenin are normally moderated by interaction with nuclear APC and axin2, which shuttle $\beta$-catenin back into the cytoplasm, and the mutation of these promote $\beta$-catenin stabilization, demonstrated in many different cancers (40). Additional mechanisms have also been described and include overexpression of FZD7 (41,42), inactivation of GSK3 $\beta$ (43), methylation of sFRP1 and $\beta$-catenin activation by receptor tyrosine kinases (44).

Immunostaining patterns of $\beta$-catenin and $\beta$-catenin-associating cell adhesion molecules in HCCs were first demonstrated by Ihara et al (45). de La Coste et al (46) demonstrated that one-quarter of human HCCs had $\beta$-catenin point mutations and deletions that led to aberrant $\beta$-catenin activation (46). In addition, $\beta$-catenin mutations were also found in hepatoma cell lines and in a subset of transgenic mouse lines of HCC. Furthermore it has been demonstrated that point mutations at specific serine and threonine residues in exon 3 are important for the aberrant activation of $\beta$-catenin in a subset of human HCCs (47). Mice expressing a mutated form of $\beta$-catenin harbouring a mutation at the serine-45 residue in exon 3 did not develop spontaneous tumours, but had increased susceptibility to developing HCCs on exposure to the carcinogen diethylnitrosamine (48). Up to $90 \%$ of HCCs have aberrant $\beta$-catenin activation in the absence of activating mutations in the CTNNB1 gene. In these tumours, there are additional mechanisms that comprise the upregulation of Wnt ligand receptors; methylation of sFRPs; mutations in components of the $\beta$-catenin destruction complex (axin1); and tyrosine-phosphorylation-dependent activation of $\beta$-catenin. All of the above are responsible for aberrant activation of $\beta$-catenin (49-51). In support of a direct role of $\beta$-catenin in hepatocarcinogenesis was the finding that aberrant activation of $\beta$-catenin by inactivating its suppressor APC led to the spontaneous development of HCCs in mice (52). On the other hand, mice overexpressing either mutated or nonmutated forms of $\beta$-catenin did not develop spontaneous tumours (53-55). Interestingly, mice with liver-specific disruption of $\beta$-catenin also showed increased diethylnitrosamine-induced hepatocarcinogenesis via increased oxidative stress and hepatocyte proliferation resulting from PDGFR $\alpha / \mathrm{PIK} 3 \mathrm{CA} / \mathrm{Akt}$ activation and $c-\mathrm{Myc}$ overexpression (56).

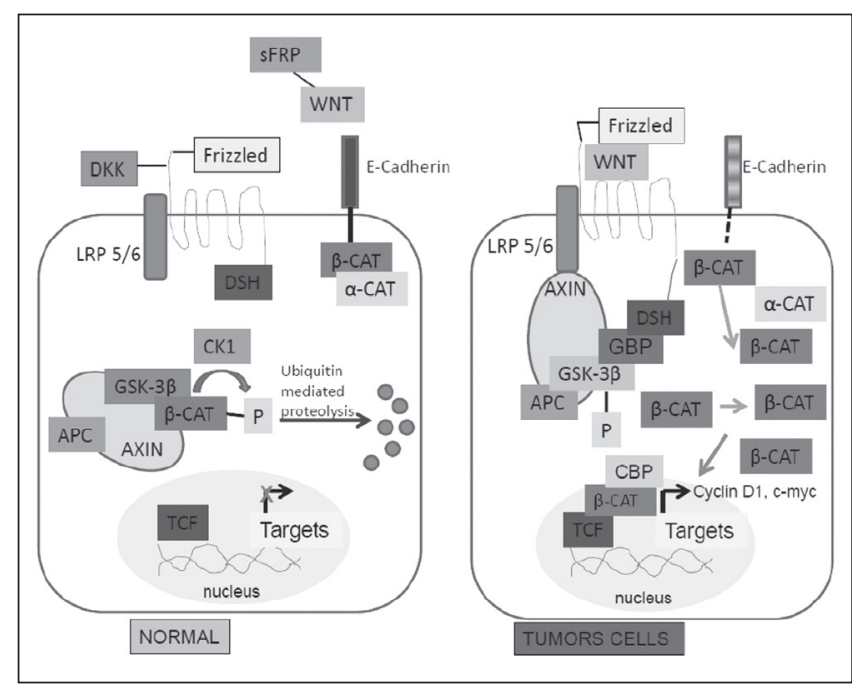

Figure 2) Illustration of the Wnt/ $\beta$-catenin signalling activation. APC Adenomatous polyposis coli; $\alpha$-cat $\alpha$-catenin; $\beta$-cat $\beta$-catenin; CBP CREB-binding protein; CK Casein kinase; DKK Dickkopf; DSH Dishevelled; GBP Glycogen synthase kinase (GSK)3-binding protein; LRP Low-density lipoprotein receptor-related protein; P Phosphorylation; sFRP Secreted frizzled-related protein; TCF T-cell factor

\section{NONCANONICAL WNT PATHWAYS}

Noncanonical Wnt pathways signalling involving or initiated by Wnt or $\mathrm{Fz}$, occurring independently of $\beta$-catenin transcriptional function (57), have not been so well clarified compared with the canonical pathway, and consist of several pathways that intersect or overlap. These include the Wnt/planar cell polarity (PCP) pathway, which activates trimeric $G$ proteins responsible for regulating actin cytoskeleton and cell adhesion, the $\mathrm{Wnt} / \mathrm{Ca}^{2+}$ signalling pathway, which regulates intracellular calcium flux via $G$ protein, the Wnt/protein kinase A signalling, which is implicated in muscle generation, and many others (58-60).

The noncanonical Wnt pathway depending on the major intracellular mediators used, are called the Wnt/c-Jun $\mathrm{N}$-terminal kinase (JNK) or Wnt/calcium pathway, respectively. The Wnt/JNK pathway has a high degree of overlap with the PCP pathway originally described in Drosophila (61). It involves activation of small GTPases of the Rho family including Rac, Cdc42 and Rho, and further downstream protein kinases such as JNK or Rho kinase. Concerning the Wnt/calcium pathway, it has been shown that purified Wnt5a is able to activate calcium signalling in different cell culture models (62-65). This process is very rapid and depends on heterotrimeric $G$ proteins. The released $\mathrm{Ca}^{2+}$ then activates calcium-dependent enzymes such as calcium/calmodulin-dependent kinase (CaMK)II, PKC or calcineurin $(66,67)$.

Through calcineurin, the Wnt/Ca ${ }^{2+}$ pathway connects to nuclear factor of activated T-cells transcription factor (63-68) and gene expression. The activation of CaMKII suggests that noncanonical Wnt signalling could modify the activity of histone deacetylase (HDAC) and that, in particular, HDAC4 and HDAC5 are regulated through CaMKII or CaMKIV (69-73).

It has been shown that activation of the $\mathrm{Wnt} / \mathrm{Ca}^{2+}$ pathway inhibits the $\mathrm{Wnt} / \beta$-catenin signalling pathway. There are several possible mechanistic actions of $\mathrm{Wnt} / \mathrm{Ca}^{2+}$-mediated inhibition of Wnt/ $\beta$-catenin signalling. One mechanism may involve the activation of Nemo-like kinase, which phosphorylates and inhibits the DNA binding ability of TCF/LEF (74). Indeed, Wnt5a inhibits Nemo-like kinase through the activation of CaMKII and transforming growth factor beta-activated kinase 1 (75). An alternative mechanism may involve Wnt5a-induced upregulation of SIAH2, 


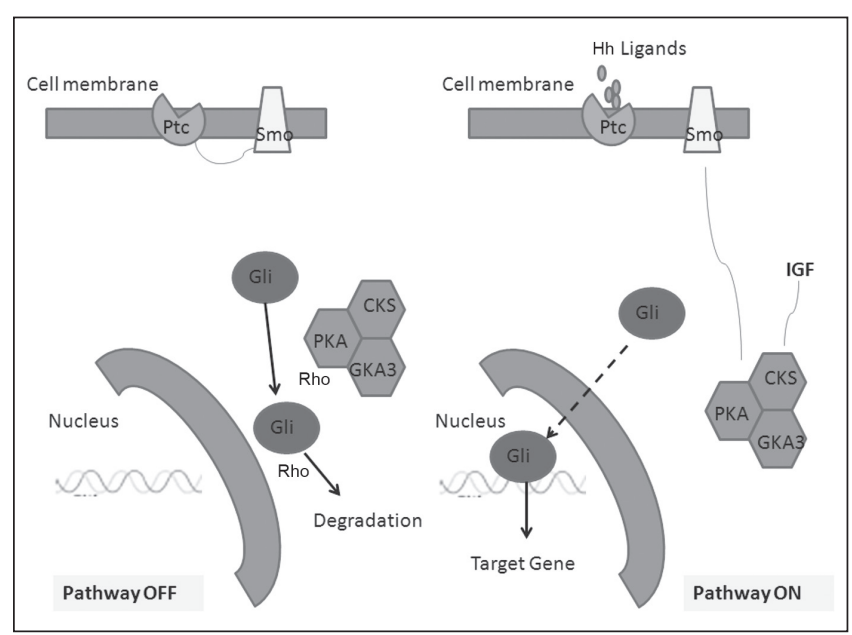

Figure 3) Overview of canonical and noncanonical Wnt signalling pathways. APC Adenomatous polyposis coli; CaCN Calcineurin; CaMKII Calcium/calmodulin-dependent kinase II; GSK Glycogen synthase kinase; IGF Insulin-like growth factor; JNK C-jun N-terminal kinase; LEF Lymphoid enhancer factor; PKA Protein kinase A; LRPL Lipoprotein receptor-related protein; NFAT Nuclear factor of activated T cells; NLK Nemo-like kinase; Ptc Patched; Smo Smoothened; TCF T-cell factor

which promotes the degradation of $\beta$-catenin (76). It has been reported that the Wnt/PCP pathway in Drosophila regulates the polarization within the plane of epithelium, which is perpendicular to the apical-basal axis (77). When stimulated by Wnt5a or Wnt11, this pathway diverges following the activation of Dishevelled and transduces signals that activate Rho and Rac, which in turn activate Rhoassociated kinase and JNK, respectively. An overview of canonical and noncanonical Wnt signalling pathway is shown in Figure 3.

\section{DickKopf-1 AND WNT SIGNALLING}

As well as an increased expression of Wnt proteins, the extracellular ligands of the Wnt/ $\beta$-catenin pathway, a decreased expression of Dickkopf (Dkk)-1 and soluble FRP, which are inhibitors of Wnt signalling, have been observed in various cancers (78). sFRP1, sFRP2, sFRP3, sFRP4, sFRP5, Wnt inhibitory factor 1, Dkk1, Dkk2, Dkk3 and Dkk4 consist of secreted-type Wnt signalling inhibitors. sFRP family members and Wnt inhibitory factor 1 are Wnt antagonists that inhibit Wnt binding to FZD family receptors, when Dkk family members demonstrate interaction with LRP5/LRP6 coreceptor and inititiate its endocytosis, resulting in the inhibition of the formation of the Wnt-FZ-LRP5/LRP6 complex for the canonical Wnt signalling (79). Epigenetic silencing of $D k k 1$, among other genes, appears to take place in premalignant tissues associated with chronic inflammation or in human cancer $(80,81)$.

Dkk1 has been shown to control Wnt signalling by its binding to the LRP receptor and blocking Wnt from binding to the receptor complex. Additionally, the expression of Dkk-1 in HeLa cells has suggested that the $D k k 1$ gene acts as a functional suppressor of cell transformation and tumourigenic growth (82-84). A possible role for Dkk1/ $\mathrm{Wnt} / \beta$-catenin cascade in the metastasis of hepatoma cells was reported by Qin et al (85), who demonstrated that overexpression of Dkk1 was able to downregulate $\beta$-catenin, c-Myc, cycline, D1, proliferating cell nuclear antigen and B-cell lymphoma 2 and, also, it inhibited the migration of $\mathrm{M}-\mathrm{H} 7402$ cells. They concluded that downregulation rather than activation of Dkk1 expression may influence cell growth, migration and malignancy, suggesting that the $\beta$-catenin pathway may contribute to the metastasis of the hepatoma cells. It was also shown that Dkk1 downregulated the expression of c-Myc, which is active in a variety of tumours and its increased expression is frequent in primary HCC. Previously, Kwack et al (86) had reported findings highlighting that Dkk-1 is expressed in some HCC cell lines and its forced expression caused growth inhibition. Contradictory to this, the overexpression of $\mathrm{Dkk} 1$ resulted in reduced cell adhesion and increased cell migration, which play a central role in tumour promotion. In recent reports it has also been demonstrated that serum and tissue Dkk1 levels increased in a stepwise manner in multistep hepatocarcinogenesis, with Dkk1 playing a functional role in cell migration, invasion and tumour growth (87). Other authors had already demonstrated that HCC patients with high Dkk1 expression and cytoplasmic/nuclear $\beta$-catenin accumulation had very poor prognosis (88). Recently, a large multicentre study concluded that Dkk1 could complement measurement of AFP in the diagnosis of HCC, and also improve the identification of patients with AFP-negative HCC and assist in distinguishing HCC from nonmalignant chronic liver diseases (89).

\section{THE HH SIGNALLING PATHWAY AND HCC}

It is well documented that signalling pathways other than Wnt/ $\beta$-catenin have central role in the development of HCC. These included the Hh signalling pathway, which has been shown to play a key role in the genesis of different malignancies, as well as in other processes, including embryogenesis and tissue repair (90), which is managed via Hh-dependent autocrine/paracrine mechanisms controlling the size and localization of Hh-responsive cell populations (9193). Moreover, possible interaction and cross-talk between Wnt/ $/$-catenin and Hh signalling in liver cancer would be expected but has not yet been clarified.

Of the three known mammalian Hh ligands, Sonic Hh (SHh), Indian $\mathrm{Hh}$ and Desert $\mathrm{Hh}$, $\mathrm{SHh}$ is considered to be the most widely expressed and most potent (94). In addition to playing a critical role in organizing cell growth and differentiation during embryonic tissue patterning (95-96), dysregulation of the Hh pathway has been implicated in the development of human malignancies of the gastrointestinal tract, including that of the pancreas and as well as HCC (97-101). Transcriptional upregulation of $\mathrm{Hh}$ ligands and epigenetic silencing of $\mathrm{Hh}$ interacting protein $1 / \mathrm{Hh}$ interacting protein gene with encoding of the Hh inhibitor, would lead to Hh signalling, in this way promoting epithelial proliferation and carcinogenesis (101).

On the other hand, Hh signalling has been shown to inhibit epithelial proliferation in the intestine because it has a negative effect on the canonical Wnt signalling pathway (102). Additionally, SHh has been highlighted as responsible for pancreatic ductal adenocarcinoma cell proliferation, epithelial-mesenchymal transition and maintenance of cancer stemness (103). Reports have also shown Hh pathway activity in cholangiocarcinoma and hepatoblastoma cell lines and also subgroups of patients with HCC $(104,105)$. Blockage of the growth of hepatoblastoma cells in culture has also been demonstrated by Hh pathway inhibitors, adding to the hypothesis that inappropriate activation of Hh signalling may have a key role in hepatocarcinogenesis. Hh-responsive cells appear to develop in the context of liver cirrhosis, which would add to the procarcinogenic role of the Hh pathway (106).

$\mathrm{SHh}$ is cleaved by proteolysis and produces two secreted proteins, a $19 \mathrm{kDa} \mathrm{N}$-terminal protein that mediates all signalling activities and a $25 \mathrm{kDa}$ C-terminal protein that possesses protease activity (107-109). The Shh signalling pathway (Figure 4) involves two transmembrane proteins, Patched (Ptc), a 12-transmembrane protein, and Smoothened (Smo), a seven-transmembrane protein with G-protein-coupled receptors, which is the signalling component of the SHh-receptor complex (110). Ptc binds with SHh, whereas Smo acts as a signal transducer. In the absence of ligands, Ptc interacts with and inhibits Smo. This inhibition activates a transcriptional repressor such as Gli protein. In the presence of ligands, the binding of SHh to Ptc prevents the inhibition of Smo, activating the transduction pathway; the interaction of Ptc and Smo is altered and Smo is no longer inhibited. The Gli protein may then enter the nucleus and function as a transcriptional activator. To regulate the SHh signalling pathway during the development of the vertebrate central nervous system, either inhibition of Gli proteins 
(111) or expression of a constitutively active form of Smo (112) is sufficient to trigger some actions of SHh. Gli-mediated transcription of SHh target genes is regulated, at least in part, by protein kinase A (113), an inhibitor of SHh activity (114). However, other studies have demonstrated that mouse Gli1 is not required for normal SHh signalling, unless one copy of Gli2 is defective, which indicates that the Gli1-3 complex is required in the SHh signalling pathway (115). Further research is required to link Smo activation to the release of transcriptionally active forms of the Gli proteins and the Hh signalling pathway may be more complicated than the canonical model suggests, because it is likely that pathway components interact with additional ligands and receptors that have yet to be identified.

\section{SHH SIGNALLING}

It has been suggested that platelet-derived growth factor, an injuryrelated cytokine released during the adult liver repair, can activate hepatic stellate cells and produce Hh ligands, with the latter inducing Hh signalling and, thus, resulting in the growth of septal myofibroblasthepatic stellate cell populations, but also neighbouring Hh-responsive cells, including certain types of epithelial progenitors (116-118). Mature hepatocytes are not Hh responsive; however, a progressive enrichment of the hepatic microenvironment with Hh ligands during the process of liver injury provides survival benefit for the Hh-responsive cells, which include myofibroblastic and progenitor cells. As Hh signalling subsides, the differentiation of Hh-responsive cells would be promoted by other factors, leading to a reaccumulation in the liver of the original, Hh-responsive populations, of liver fibrosis and HCC (118).

The Hh pathway plays key roles in several cellular events as well as cell proliferation (119); namely, inhibition of apoptosis (120), invasiveness and metastasis $(121,122)$. Activation of the SHh pathway appears to be important on both the development and the progression of HCC $(123,124)$. Ptc and Gli-1 are downstream target genes of the Hh pathway; thus, their transcript indicates $\mathrm{Hh}$ signalling activation. Chen et al (125) found that SHh signal pathway activation was associated with tumour size, capsular invasion and vascular invasion. In another study, Chen et al (126) also demonstrated that SHh pathway induced cell migration and invasion through focal adhesion kinase/Akt signalling-mediated matrix metalloproteinase- 2 and matrix metalloproteinase- 9 production and activation in liver cancer. Tada et al (127) regarded the overexpression of Smoh or SHh as being positive regulators and the major trigger for the activation of this signalling pathway, mediating $\mathrm{c}$-myc overexpression and playing a critical role in hepatocarcinogenesis. Ptc-1 activation predisposes a cell to proliferative and activates Smo, an intracellular substrate that migrates to the cellular membrane. At the cellular membrane, the activated Smo triggers the downstream transcription of Gli-1 proteins (128-129). Aberrant activation of the SHh pathway leads Gli-1 into the nucleus to promote gene transcription and to maintain the biological behaviours of cancer cells. Activation of the SHh pathway may also occur in different stages of the same cancer. Thus, Huang et al (130) suggested that the activation occurs in the early stage of HCC, whereas Thayer et al (131) considered that $\mathrm{Hh}$ is both a late mediator as well as an early mediator in pancreatic carcinogenesis.

\section{NoTCH SIGNALLING PATHWAY}

The Notch signalling pathway is a highly conserved signalling pathway, plays a key role in cell-cell communications and regulates multiple cell differentiation processes during embryonic development and throughout adulthood $(132,133)$. In the liver, Notch coordinates biliary fate and morphogenesis (134). Notch signalling has been shown to play an important role in many types of human cancers, including T-cell leukemia, lymphoma, colorectal, pancreatic, ovarian, lung, cervical, breast and other types of cancer (135-138). The involvement of Notch in cancer development is complex, because Notch can function as an oncogene or a tumour suppressor depending on the tissue and on the

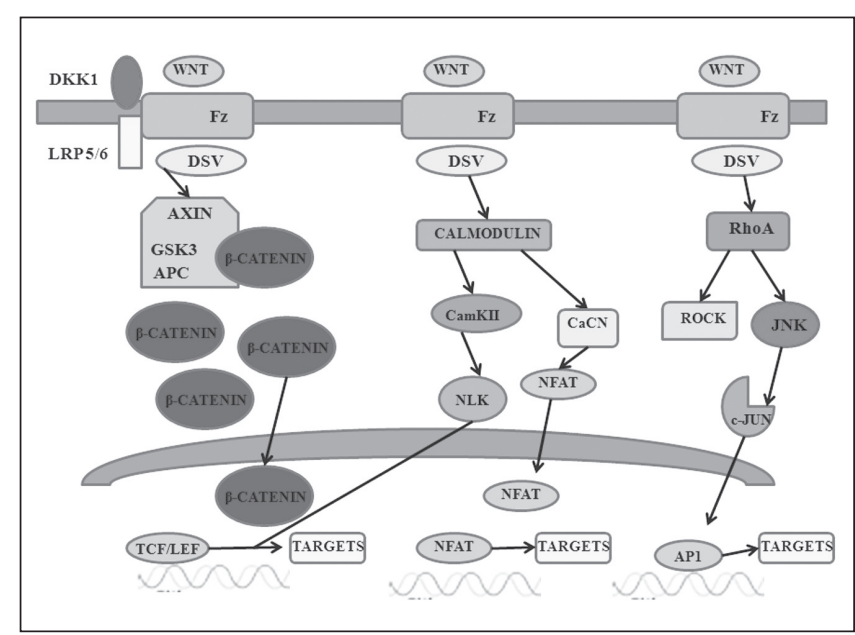

Figure 4) Illustration of the Hedghog (Hh) signalling activation. Hh pathway is silent when Hh ligands are absent. Hh signalling is initiated by a family of ligands (Sonic Hh, Indian Hh and Desert Hh) that interact with a cell-surface receptor (Patched [Ptc]; Smoothened [Smo]) and other intracellular factors, permitting the stabilization and accumulation of glioblastoma (Gli) transcription factors. Gli proteins undergo phosphorylation by various intracellular kinases (protein kinase A, glycogen synthase kinase 3ß, glycogen sythanse kinase [GSK]), become ubiquitinated, and degrade. APC Adenomatous polyposis coli; CaCN Calcineurin; DKK1 Dickkopf1; DSV Dishevelled; Fz Frizzled; JNK C-jun N-terminal kinase; LEF Lymphoid enhancer factor; LRP5/6 Low-density lipoprotein receptor-related protein 5/6; NLK Nemo-like kinase; NFAT Nuclear factor of activated T cells; ROCK Rho-associated kinase; TCF T-cell factor

presence of different signalling pathways (139). Notch signalling is activated through four receptors (Notch1, 2, 3 and 4) that can interact in a redundant manner with five ligands of the Delta/Jagged family $(140,141)$. Two studies have demonstrated that Notch1 overexpression inhibits HCC cell growth by promoting cell cycle arrest and apoptosis $(142,143)$. On the contrary, other evidence suggests an oncogenic role for Notch activation in hepatocarcinogenesis (144), and in the work of Giovannini et al (145) significant over-expression of Notch1 and Notch3 was detected through immunohistochemistry in 60 HCCs.

Notch signalling was initially identified in human T-cell leukemia. Direct Notch inhibition has been found to have antiproliferative effects on T-cell acute lymphoblastic leukemia $(146,147)$. Wang et al (148) showed that low expression levels of Notch1/Jagged1 were frequently observed, and that downregulation of Notch1/Jagged1 signalling may sustain tumour progression in HCC. Upregulation of Notch1 was also shown to retard hepatocarcinogenesis by arresting the cell cycle and inducing apoptosis and, in addition, high Notch3 and low Notch4 expression levels may be associated with HCC.

Notch1 has been reported to participate in cross-talk with other signalling pathways such as Ras/Raf/MEK/ERK through the regulation of the PTEN tumour suppressor (149), and that activation of Notch1 signalling increases the expression level of death receptor 5 with enhancement of tumour necrosis factor-related apoptosisinducing ligand-induced apoptosis in vitro and in vivo $(143,150)$.

It has also been demonstrated that Notch exhibits crosstalk with Wnt/ß-catenin signalling in many cell types during development (151) The interaction of Notch and Wnt signalling was first found in the Drosophila wing imaginal disc, where Notch is coexpressed with Wnt1 (152) The interaction between Notch and Wnt/ $\beta$-catenin signalling may occur in synergic or antagonistic ways, depending on the context (153).

Notch physically interacts with $\beta$-catenin and modulates Wnt signalling by negatively regulating $\beta$-catenin activity in flies (154) exhibiting the antagonism of Wnt signalling by uncleaved Notch without involving Notch ligands and CSL. In addition, Notch functions both 
as a membrane transcription factor and as membrane-bound regulator by lowering levels of the transcriptionally active form of $\beta$-catenin (155-157). This form of $\beta$-catenin is dephosphorylated at Ser37 and Thr41 and normally constitutes a small fraction of total $\beta$-catenin (158). In mammalian stem and progenitor cells, Notch levels are inversely correlated with active $\beta$-catenin $(154,159)$. The RAM domain, which is the CSL-binding domain of Notch, is required for the physical interaction and regulation of active $\beta$-catenin $(155,160)$. Membrane Notch regulation of active $\beta$-catenin occurred independent of GSK3 $\beta,(161,162)$, and genetic analyses revealed that membrane Notch was able to downregulate increased $\beta$-catenin activity resulting from GSK3 $\beta$ loss of function (154). On the other hand, a recent study suggested that axin and APC participate in this regulation by modulating endocytosis and trafficking of membrane Notch (163).

DISCLOSURES: The authors have no financial disclosures or conflicts of interest to declare.

\section{REFERENCES}

1. El-Serag HB, Rudolph KL. Hepatocellular carcinoma: Epidemiology and molecular carcinogenesis. Gastroenterology 2007;132:2557-76.

2. Farazi PA, DePinho RA. Hepatocellular carcinoma pathogenesis: From genes to environment. Nat Rev Cancer 2006;6:674-87.

3. Villanueva A, Newell P, Chiang DY, et al. Genomics and signalling pathways in hepatocellular carcinoma. Semin Liver Dis 2007;27:55-76

4. Wong CM, Ng IO. Molecular pathogenesis of hepatocellular carcinoma. Liver Int 2008;28:160-74.

5. Laurent-Puig P, Zucman-Rossi J. Genetics of hepatocellular tumors. Oncogene 2006;25:3778-86.

6. Bressac B, Kew M, Wands J, et al. Selective G to T mutations of p53 gene in hepatocellular carcinoma from southern Africa. Nature 1991;350:429-31.

7. Hsu IC, Metcalf RA, Sun T, et al. Mutational hotspot in the p53 gene in human hepatocellular carcinomas. Nature 1991;350:427-8.

8. de La Coste A, Romagnolo B, Billuart P, et al. Somatic mutations of the beta-catenin gene are frequent in mouse and human hepatocellular carcinomas. Proc Natl Acad Sci USA 1998;95:8847-51.

9. Yao YJ, Ping XL, Zhang H, et al. PTEN/MMAC1 mutations in hepatocellular carcinomas. Oncogene 1999;18:3181-5.

10. Zender L, Villanueva A, Tovar V, et al. Cancer gene discovery in hepatocellular carcinoma. J Hepatol 2010;52:921-9.

11. Sharma RP, Chopra VL. Effect of the Wingless (wg1) mutation on wing and haltere development in Drosophila melanogaster. Dev Biol 1976; 48:461-5.

12. Nusse R, Varmus HE. Many tumors induced by the mouse mammary tumor virus contain a provirus integrated in the same region of the host genome. Cell 1982;31:99-109.

13. Kimelman D, Xu W. Beta-catenin destruction complex: Insights and questions from a structural perspective. Oncogene 2006;25:7482-91.

14. Katoh M. WNT and FGF gene clusters. Int J Oncol 2002;21:1269-73.

15. Logan CY, Nusse R. The Wnt signalling pathway in development and disease. Annu Rev Cell Dev Biol 2004;20:781-810.

16. Wolfe A, Thomas A, Edwards G, et al. Increased activation of the Wnt/ $\beta$-catenin pathway in spontaneous hepatocellular carcinoma observed in farnesoid X receptor knockout mice. J Pharmacol Exp Ther 2011;338:12-21.

17. Calvisi DF, Factor VM, Ladu S, et al. Disruption of beta-catenin pathway or genomic instability define two distinct categories of liver cancer in transgenic mice. Gastroenterology 2004;126:1374-86.

18. Devereux TR, Stern MC, Flake GP, et al. CTNNB1 mutations and beta-catenin protein accumulation in human hepatocellular carcinomas associated with high exposure to aflatoxin B1. Mol Carcinog 2001;31:68-73.

19. Nejak-Bowen K, Monga SP. Wnt/ $\beta$-catenin signalling in hepatic organogenesis. Organogenesis 2008;4:92-9.

20. Thompson MD, Monga SP. WNT/beta-catenin signalling in liver health and disease. Hepatology 2007;45:1298-305.

21. Zeng G, Awan F, Otruba W, et al. Wnt'er in liver: Expression of Wnt and Frizzled genes in mouse. Hepatology 2007;45:195-204.

22. Kondo Y, Kanai Y, Sakamoto M, et al. $\beta$-catenin accumulation and

\section{CONCLUSION}

Understanding the complex signalling pathway and the pathophysiology of hepatocarcinogenesis is of paramount importance for the identification of specific targets for therapeutic intervention. Wnt/ $\beta$ catenin, Hh and Notch signalling pathways act in controlling progenitor cell growth and promote liver inflammation and fibrinogenic repair and, thereafter, hepatocarcinogenesis. Possible cross-talk between different signalling pathways in liver cancer development could lead in a combination of treatment agents and increase the efficacy of therapeutic interventions. Further studies are needed to explore the use of small molecules, targeted particularly to the Wnt/ $\beta$-catenin Hh and Notch pathways and to clarify exact mechanisms of cross-talk between these pathways. mutation of exon 3 of the $\beta$-catenin gene in hepatocellular carcinoma. Jpn J Cancer Res 1999;90:1301-9.

23. Wong CM, Fan ST, Ng IO. $\beta$-catenin mutation and overexpression in hepatocellular carcinoma: Clinicopathologic and prognostic significance. Cancer 2001;92:136-45.

24. Kim M, Lee HC, Tsedensodnom O, et al. Functional interaction between Wnt3 and Frizzled-7 leads to activation of the Wnt/ $\beta$ catenin signalling pathway in hepatocellular carcinoma cells. J Hepatol 2008;48:780-91.

25. Yuzugullu H, Benhaj K, Ozturk N, et al. Canonical Wnt signalling is antagonized by noncanonical Wnt5a in hepatocellular carcinoma cells. Mol Cancer 2009;22;8:90.

26. Hsu HC, Jeng YM, Mao TL, et al. Beta-catenin mutations are associated with a subset of low-stage hepatocellular carcinoma negative for hepatitis $B$ virus and with favorable prognosis. AmJ Pathol 2000;157:763-70.

27. Zucman-Rossi J, Benhamouche S, Godard C, et al. Differential effects of inactivated Axin1 and activated beta-catenin mutations in human hepatocellular carcinomas. Oncogene 2007;26:774-80.

28. Panakova D, Sprong H, Marois E, et al. Lipoprotein particles are required for Hedgehog and Wingless signalling. Nature 2005;435:58-65.

29. Franch-Marro X, Marchand O, Piddini E, et al. Glypicans shunt the Wingless signal between local signalling and further transport. Development 2005;132:659-66.

30. Zucman-Rossi J, Benhamouche S, Godard C, et al. Differential effects of inactivated Axin 1 and activated beta-catenin mutations in human hepatocellular carcinomas. Oncogene 2007;26:774-80.

31. Hsu IC, Metcalf RA, Sun T, et al. Mutational hotspot in the p53 gene in human hepatocellular carcinomas. Nature 1991;350:427-8.

32. Fujie H, Moriya K, Shintani Y, et al. Frequent beta-catenin aberration in human hepatocellular carcinoma. Hepatol Res 2001;20:39-51.

33. Huang H, Fujii H, Sankila A, et al. Beta-catenin mutations are frequent in human hepatocellular carcinomas associated with hepatitis C virus infection. Am J Pathol 1999;155:1795-801.

34. Kim YD, Park CH, Kim HS, et al. Genetic alterations of Wnt signalling pathway-associated genes in hepatocellular carcinoma. J Gastroenterol Hepatol 2008;23:110-8.

35. Kondo Y, Kanai Y, Sakamoto M, et al. Betacatenin accumulation and mutation of exon 3 of the beta-catenin gene in hepatocellular carcinoma. Jpn J Cancer Res 1999; 90:1301-9.

36. Satoh S, Daigo Y, Furukawa Y, et al. AXIN1 mutations in hepatocellular carcinomas, and growth suppression in cancer cells by virus-mediated transfer of AXIN1. Nat Genet 2000;24:245-50.

37. Taniguchi K, Roberts LR, Aderca IN, et al. Mutational spectrum of beta-catenin, AXIN1, and AXIN2 in hepatocellular carcinomas and hepatoblastomas. Oncogene 2002;21:4863-71.

38. Latres E, Chiaur DS and Pagano M. The human F box protein betaTrcp associates with the Cul1/Skp1 complex and regulates the stability of beta-catenin. Oncogene 1999;18:849-54.

39. Liu C, Kato Y, Zhang Z et al. beta-Trcp couples betacatenin phosphorylation-degradation and regulates Xenopus axis formation. Proc Natl Acad Sci USA 1999;96:6273-8.

40. Polakis P. The many ways of Wnt in cancer. Curr Opin Genet Dev 2007;17:45-51. 
41. Merle P, de la Monte S, Kim M, et al. Functional consequences of frizzled-7 receptor overexpression inhuman hepatocellular carcinoma. Gastroenterology 2004;127:1110-22.

42. Nambotin SB, Lefrancois L, Sainsily X, et al. Pharmacological inhibition of Frizzled-7 displays anti-tumor properties in hepatocellular carcinoma. J Hepatol 2011;54:288-99.

43. Ban KC, Singh H, Krishnan R, et al. GSK-3beta phosphorylation and alteration of beta-catenin in hepatocellular carcinoma. Cancer Lett 2003;199:201-8.

44. Cieply B, Zeng G, Proverbs-Singh T, et al. Unique phenotype of hepatocellular cancers with exon-3 mutations in beta-catenin gene. Hepatology 2009;49:821-31.

45. Ihara A, Koizumi H, Hashizume R, et al. Expression of epithelial cadherin and $\alpha$ - and $\beta$-catenins in nontumoral livers and hepatocellular carcinomas. Hepatology 1996;23:1441-7.

46. de La Coste A, Romagnolo B, Billuart P, et al. Somatic mutations of the $\beta$-catenin gene are frequent in mouse and human hepatocellular carcinomas. Proc Natl Acad Sci USA 1998; 95:8847-51.

47. Monga SP. Role of Wnt/ $/$-catenin signalling in liver metabolism and cancer. Int J Biochem Cell Biol 2011;43:1021-9.

48. Nejak-Bowen KN, Thompson MD, Singh S, et al. Accelerated liver regeneration and hepatocarcinogenesis in mice overexpressing serine-45 mutant $\beta$-catenin. Hepatology 2010;51:1603-3.

49. Kondo Y, Kanai Y, Sakamoto M, et al. $\beta$-catenin accumulation and mutation of exon 3 of the $\beta$-catenin gene in hepatocellular carcinoma. Jpn J Cancer Res 1999;90:1301-9.

50. Legoix $\mathrm{P}$, Bluteau $\mathrm{O}$, Bayer J, et al. $\beta$-catenin mutations in hepatocellular carcinoma correlate with a low rate of loss of heterozygosity. Oncogene 1999;18:4044-6.

51. Cheng JH, She H, Han YP, et al. Wnt antagonism inhibits hepatic stellate cell activation and liver fibrosis. Am J Physiol Gastrointest Liver Physiol 2008;294:G39-49.

52. Colnot S, Decaens T, Niwa-Kawakita M, et al. Liver-targeted disruption of APC in mice activates $\beta$-catenin signalling and leads to hepatocellular carcinomas. Proc Natl Acad Sci USA 2004;101:17216-21.

53. Tan X, Apte U, Micsenyi A, et al. Epidermal growth factor receptor: a novel target of the $\mathrm{Wnt} / \beta$-catenin pathway in liver. Gastroenterology. 2005;129:285-302.

54. Cadoret A, Ovejero C, Terris B, et al. New targets of $\beta$-catenin signalling in the liver are involved in the glutamine metabolism. Oncogene 2002;21:8293-301.

55. Harada N, Miyoshi H, Murai N, et al. Lack of tumorigenesis in the mouse liver after adenovirusmediated expression of a dominant stable mutant of $\beta$-catenin. Cancer Res. 2002;62:1971-7.

56. Zhang XF, Tan X, Zeng G, et al. Conditional $\beta$-catenin loss in mice promotes chemical hepatocarcinogenesis: Role of oxidative stress and platelet-derived growth factor receptor $\alpha /$ phosphoinositide 3-kinase signalling. Hepatology 2010; 52:954-65.

57. Semenov MV, Habas R, Macdonald BT, He X. SnapShot: Noncanonical Wnt signalling pathways. Cell 2007;131:1378.

58. Tada M, Kai M. Noncanonical Wnt/PCP signalling during vertebrate gastrulation. Zebrafish 2009;6:29-40.

59. Jessen JR. Noncanonical Wnt signalling in tumor progression and metastasis. Zebrafish 2009;6:21-8.

60. Wada H, Okamoto H. Roles of noncanonical Wnt/PCP pathway genes in neuronal migration and neurulation in zebrafish. Zebrafish 2009;6:3-8.

61. Simons M, Mlodzik M. Planar cell polarity signalling: From fly development to human disease. Annu Rev Genet 2008;42:517-40.

62. Kremenevskaja N, von Wasielewski R, Rao AS, et al. Wnt-5a has tumor suppressor activity in thyroid carcinoma. Oncogene 2005;24:2144-54.

63. Dejmek J, Safholm A, Kamp Nielsen C, et al. Wnt-5a/Ca ${ }^{2+}$, induced NFAT activity is counteracted by Wnt-5a/Yes-Cdc42casein kinase 1alpha signalling in human mammary epithelial cells. Mol Cell Biol 2006;26:6024-36.

64. Ma L, Wang HY. Suppression of cyclic GMP-dependent protein kinase is essential to the $\mathrm{Wnt} / \mathrm{cGMP} / \mathrm{Ca}^{2+}$-pathway. J Biol Chem 2006;281:30990-1001.

65. Saefholm A, Leandersson K, Dejmek J, et al A formylated hexapeptide ligand mimics the ability of Wnt-5a to impair migration of human breast epithelial cells. J Biol Chem 2006;281:2740-9.

66. Kuhl M, Sheldahl LC, Malbon CC, et al. $\mathrm{Ca}(2+)$ / calmodulindependent protein kinase II is stimulated by Wnt and
Frizzled homologs and promotes ventral cell fates in Xenopus. J Biol Chem 2000;275:12701-11.

67. Kuhl M, Sheldahl LC, Park M, et al. The Wnt/Ca ${ }^{2+}$ pathway: A new vertebrate $\mathrm{Wnt}$ signalling pathway takes shape. Trends Genet 2000;16:279-83.

68. Saneyoshi T, Kume S, Amasaki Y, et al. The Wnt/calcium pathway activates NF-AT and promotes ventral cell fate in Xenopus embryos. Nature 2002;417:295-9.

69. Karamboulas C, Swedani A, Ward C, et al. HDAC activity regulates entry of mesoderm cells into the cardiac muscle lineage. J Cell Sci 2006;119:4305-14.

70. Zhang T, Kohlhaas M, Backs J, et al. CaMKII delta isoforms differentially affect calcium handling but similarly regulate HDAC/MEF2 transcriptional responses. J Biol Chem 2007;282:35078-87.

71. Backs J, Song K, Bezprozvannaya S, et al. CaM kinase II selectively signals to histone deacetylase 4 during cardiomyocyte hypertrophy. J Clin Invest 2006;116:1853-64.

72. Backs J, Backs T, Bezprozvannaya S, et al. Histone deacetylase 5 acquires calcium/calmodulin-dependent kinase II responsiveness by oligomerization with histone deacetylase 4 . Mol Cell Biol 2008;28:3437-45.

73. Little GH, Bai Y, Williams T, et al. Nuclear calcium/ calmodulindependent protein kinase IIdelta preferentially transmits signals to histone deacetylase 4 in cardiac cells. J Biol Chem 2007;282:7219-31.

74. Goodwin AM, D'Amore PA. Wnt signalling in the vasculature. Angiogenesis 2002;5:1-9.

75. Bullions LC, Levine AJ. The role of beta-catenin in cell adhesion, signal transduction, and cancer. Curr Opin Oncol 1998;10:81-7.

76. Du C, Jaggi M, Zhang C, et al. Protein kinase D1-mediated phosphorylation and subcellular localization of beta-catenin. Cancer Res 2009;69:1117-24.

77. Dupre-Crochet S, Figueroa A, Hogan C, et al. Casein kinase 1 is a novel negative regulator of E-cadherin-based cell-cell contacts. Mol Cell Biol 2007;27:3804-16.

78. Kolligs FT, Bommer G, Goke B. Wnt/beta-catenin/tcf signalling: A critical pathway in gastrointestinal tumorigenesis. Digestion 2002;66:131-44.

79. Kawano Y, Kypta R. Secreted antagonists of the Wnt signalling pathway. J Cell Sci 2003;116:2627-34.

80. Katoh M, Katoh M. Cross-talk of WNT and FGF signalling pathways at GSK3h to regulate beta-catenin and SNAIL signalling cascades. Cancer Biol Ther 2006;5:1059-64.

81. Suzuki H, Gabrielson E, ChenW, et al. A genomic screen for genes up-regulated by demethylation and histone deacetylase inhibition in human colorectal cancer. Nat Genet 2002;31:141-9.

82. Mao B, Wu W, Li Y, et al. LDL-receptor-related protein 6 is a receptor for Dickkopf proteins. Nature 2001;411:321-5.

83. Bafico A, Liu G, Yaniv A, et al. Novel mechanism of Wnt signalling inhibition mediated by Dickkopf-1 interaction with LRP6/Arrow. Nat Cell Biol 2001;3:683-6.

84. Mikheev AM, Mikheeva SA, Liu B, et al H. A functional genomics approach for the identification of putative tumor suppressor genes: Dickkopf-1 as suppressor of Hela cell transformation. Carcinogenesis 2004;25:47-59.

85. Qin X, Zhang H, Zhou X, et al. Proliferation and migration mediated by Dkk-1/Wnt/beta-catenin cascade in a model of hepatocellular carcinoma cells. Transl Res 2007;150:281-94.

86. Kwack MH, Hwang SY, Jang IS, et al. Analysis of cellular changes resulting from forced expression of Dickkopf-1 in hepatocellular carcinoma cells. Cancer Res Treat 2007;39:30-6.

87. Tung EK, Mak CK, Fatima S, et al. Clinicopathological and prognostic significance of serum and tissue Dickkopf-1 levels in human hepatocellular carcinoma. Liver Int 2011;31:1494-504.

88. Yu B, Yang X, Xu Y, et al. Elevated expression of DKK1 is associated with cytoplasmic/nuclear beta-catenin accumulation and poor prognosis in hepatocellular carcinomas. J Hepatol 2009;50:948-57.

89. Shen Q, Fan J, Yang XR, et al. Serum DKK1 as a protein biomarker for the diagnosis of hepatocellular carcinoma: A large-scale, multicentre study. Lancet Oncol 2012;13:817-26.

90. Lum L and Beachy PA: The Hedgehog response network: Sensors, switches, and routers. Science 2004;304:1755-9.

91. Beachy PA, Karhadkar SS, Berman DM. Tissue repair and stem cell renewal in carcinogenesis. Nature 2004;432:324-31. 
92. Deutsch G, Jung J, Zheng M, et al. A bipotential precursor population for pancreas and liver within the embryonic endoderm. Development 2001;128:871-81.

93. Omenetti A, Diehl AM. The adventures of sonic hedgehog in development and repair. II. Sonic hedgehog and liver development, inflammation, and cancer. Am J Physiol Gastrointest Liver Physiol 2008;294:G595-8.

94. Ruiz I, Altaba A., Sanchez P, et al. Gli and hedgehog in cancer: Tumours, embryos and stem cells. Nat Rev Cancer 2002;2:361-72.

95. Agathocleous M, Locker M, Harris WA, et al. A general role of hedgehog in the regulation of proliferation. Cell Cycle 2007;6:156-9.

96. Ingham PW. Transducing hedgehog: The story so far. EMBO J 1998;17:3505-11.

97. Harmon EB, Ko AH, Kim SK. Hedgehog signalling in gastrointestinal development and disease. Curr Mol Med 2002;2:67-82.

98. Thayer SP, diMagliano MP, Heiser PW, et al. Hedgehog is an early and late mediator of pancreatic cancer tumorigenesis. Nature 2003;425:851-6.

99. Karhadkar SS, Bova GS, Abdallah N, et al. Hedgehog signalling in prostate regeneration, neoplasia and metastasis. Nature 2004:431:707-12.

100. Ma X, Sheng T, Zhang Y, et al. Hedgehog signalling is activated in subsets of esophageal cancers. Int J Cancer 2006;118:139-48.

101. Jeng KS, Sheen IS, Jeng WJ, et al. High expression of patched homolog-1 messenger RNA and glioma-associated oncogene-1 messenger RNA of sonic hedgehog signalling pathway indicates a risk of postresection recurrence of hepatocellular carcinoma. Ann Surg Oncol 2013;20:464-73.

102. Katoh Y, Katoh M. Hedgehog target genes: Mechanisms of carcinogenesis induced by aberrant hedgehog signalling activation. Curr Mol Med 2009;9:873-86.

103. Leask A. Sonic advance: CCN1 regulates sonic hedgehog in pancreatic cancer. J Cell Commun Signal 2013;7:61-2.

104. Beachy PA, Karhadkar SS, Berman DM. Tissue repair and stem cell renewal in carcinogenesis. Nature 2004;432:324-31.

105. Sicklick JK, Li YX, Jayaraman A, et al. Dysregulation of the Hedgehog pathway in human hepatocarcinogenesis. Carcinogenesis 2006;27:748-57.

106. Omenetti A, Diehl AM. The adventures of sonic hedgehog in development and repair. II. Sonic hedgehog and liver development, inflammation, and cancer. Am J Physiol Gastrointest Liver Physiol 2008;294:G595-8.

107. Chuang P-T, McMahon AP. Vertebrate hedgehog signalling modulated by induction of a hedgehog-binding protein. Nature 1999;397:617-21.

108. Johnson R, Tabin C. The long and short of hedgehog signalling. Cell 1995;81:313-6.

109. Porter JA, von Kessler DP, Ekker SC, et al. The product of hedgehog auto-proteolytic cleavage active in local and long-range signalling. Nature 1995;1995;374:363-6.

110. Murone M, Rosenthal A, de Sauvage FJ. Sonic hedgehog signalling by the patched-smoothened receptor complex. Curr Biol 1999;9:76-84.

111. Hammerschmidt M, McMahon AP. The effect of pertussis toxin on zebrafish development: A possible role for inhibitory G-proteins in hedgehog signalling. Dev Biol 1998;194:166-71.

112. Hynes M, Ye W, Wang K, et al. The seven-transmembrane receptor smoothened cell-autonomously induces multiple ventral cell types. Nat Neurosci 2000;3:41-6.

113. Kaesler S, Lüscher B, Rüther U. Transcriptional activity of GLI1 is negatively regulated by protein kinase $\mathrm{A}$. Biol Chem 2000;381:545-51.

114. Hammerschmidt M, Bitgood MJ, McMahon AP. Protein kinase A is a common negative regulator of Hedgehog signalling in the vertebrate embryo. Genes Dev 1996;10:647-58.

115. Bai CB, Auerbach W, Lee JS, et al. Gli2, but not Gli1, is required for initial Shh signalling and ectopic activation of the Shh pathway. Development 2002;129:4753-61.

116. Beachy PA, Karhadkar SS, Berman DM. Tissue repair and stem cell renewal in carcinogenesis. Nature 2004;432:324-31.

117. Sicklick JK, Li YX, Jayaraman A, et al. Dysregulation of the Hedgehog pathway in human hepatocarcinogenesis. Carcinogenesis 2006;27:748-57.

118. Omenetti A, Diehl AM. The adventures of sonic hedgehog in development and repair. II. Sonic hedgehog and liver development, inflammation, and cancer. Am J Physiol Gastrointest Liver Physiol 2008;294:G595-8.

119. Regl G, Kasper M, Schnidar H, et al. The zinc-finger transcription factor GLI2 antagonizes contact inhibition and differentiation of human epidermal cells. Oncogene 2004;23:1263-74.

120. Bigelow RL, Chari NS, Unden AB, et al. Transcriptional regulation of bcl-2 mediated by the Sonic hedgehog signalling pathway through Gli-1. J Biol Chem 2004;279:1197-205.

121. Karhadkar SS, Bova GS, Abdallah N, et al. Hedgehog signalling in prostate regeneration, neoplasia and metastasis. Nature 2004;431:707-12.

122. Jeng KS, Sheen IS, Jeng WJ, et al. High expression of patched homolog-1 messenger RNA and glioma-associated oncogene-1 messenger RNA of sonic hedgehog signalling pathway indicates a risk of postresection recurrence of hepatocellular carcinoma. Ann Surg Oncol 2013;20:464-73.

123. Sicklick JK, Li YX, Jayaraman A, et al. Dysregulation of the hedgehog pathway in human hepatocarcinogenesis. Carcinogenesis 2006;27:748-57.

124. Patil MA, Zhang J, Ho C, et al. Hedgehog signalling in human hepatocellular carcinoma. Cancer Biol Ther 2006;5:111-7.

125. Chen XL, Cheng QY, She MR, et al. Expression of sonic hedgehog signalling components in hepatocellular carcinoma and cyclopamine-induced apoptosis through $\mathrm{Bcl}-2$ downregulation in vitro. Arch Med Res 2010;41:315-23.

126. Chen JS, Huang XH, Wang Q, et al. Sonic hedgehog signalling pathway induces cell migration and invasion through focal adhesion kinase/AKT signalling-mediated activation of matrix metalloproteinase (MMP)-2 and MMP-9 in liver cancer. Carcinogenesis 2013;34:10-9.

127. Tada M, Kanai F, Tanaka Y, et al. Down-regulation of hedgehog interacting protein through genetic and epigenetic alterations in human hepatocellular carcinoma. Clin Cancer Res 2008;14:3768-76.

128. Taipale J, Beachy PA. The Hedgehog and Wnt signalling pathways in cancer. Nature 2001;411:349-54.

129. Adolphe C, Hetherington R, Ellis T, et al. Patched1 functions as a gatekeeper by promoting cell cycle progression. Cancer Res 2006;66:2081-8.

130. Huang S, He J, Zhang X, et al. Activation of the hedgehog pathway in human hepatocellular carcinomas. Carcinogenesis 2006;27:1334-40.

131. Thayer SP, di Magliano MP, Heiser PW, et al. Hedgehog is an early and late mediator of pancreatic cancer tumorigenesis. Nature 2003;425:851-6.

132. Radtke F, Raj K. The role of Notch in tumorigenesis: Oncogene or tumour suppressor? Nat Rev Cancer 2003;3:756-67.

133. Zaret KS. Genetic programming of liver and pancreas progenitors: Lessons for stem-cell differentiation. Nat Rev Genet 2008;9:329-40.

134. Zong Y, Panikkar A, Xu J, et al. Notch signalling controls liver development by regulating biliary differentiation. Development 2009;136:1727-39.

135. Yin L, Velazquez OC, Liu ZJ. Notch signalling: Emerging molecular targets for cancer therapy. Biochem Pharmacol 2010;80:690-701.

136. Sharma VM, Draheim KM, Kelliher MA. The Notch1/c-Myc pathway in T cell leukemia. Cell Cycle 2007;6:927-30.

137. Moserle L, Ghisi M, Amadori A, et al. Side population and cancer stem cells: Therapeutic implications. Cancer Lett 2010;288:1-9.

138. Wu WK, Cho CH, Lee CW, et al. Dysregulation of cellular signalling in gastric cancer. Cancer Lett 2010;295:144-153.

139. Weng AP, Aster JC. Multiple niches for Notch in cancer: Context is everything. Curr Opin Genet Dev 2004;14:48-54.

140. Cerdan C, Bhatia M. Novel roles for Notch, Wnt and Hedgehog in hematopoesis derived from human pluripotent stem cells. Int J Dev Biol 2010;54:955-63.

141. Bray SJ. Notch signalling: A simple pathway becomes complex. Nat Rev Mol Cell Biol 2006;7:678-89.

142. Qi R, An H, Yu Y, et al. Notch1 signalling inhibits growth of human hepatocellular carcinoma through induction of cell cycle arrest and apoptosis. Cancer Res 2003;63:8323-9.

143. Wang C, Qi R, Li N, et al. Notch1 signalling sensitizes tumor necrosis factor-related apoptosis-inducing ligand-induced apoptosis in human hepatocellular carcinoma cells by inhibiting Akt/Hdm2mediated 553 degradation and up-regulating p53-dependent DR5 expression. J Biol Chem 2009;284:16183-90.

144. Villanueva A, Alsinet C, Yanger K, et al. Notch signalling is activated in human hepatocellular carcinoma and induces tumor formation in mice. Gastroenterology 2012;143:1660-9. 
145. Giovannini C, Gramantieri L, Chieco P, et al. Selective ablation of Notch3 in HCC enhances doxorubicin's death promoting effect by a p53 dependent mechanism. J Hepatol 2009;50:969-79.

146. Moellering RE, Cornejo M, Davis TN, et al. Direct inhibition of the NOTCH transcription factor complex. Nature 2009;462:182-8.

147. Arora PS, Ansari AZ. Chemical biology: A Notch above other inhibitors. Nature 2009;462:171-3.

148. Wang M, Xue L, Cao Q, et al. Expression of Notch1, Jagged1 and beta-catenin and their clinicopathological significance in hepatocellular carcinoma. Neoplasma 2009;56:533-41.

149. Chappell WH, Green TD, Spengeman JD, et al. Increased protein expression of the PTEN tumor suppressor in the presence of constitutively active Notch-1. Cell Cycle 2005;4:1389-95.

150. Portanova P, Notaro A, Pellerito O, et al. Notch inhibition restores TRAIL-mediated apoptosis via AP1-dependent upregulation of DR4 and DR5 TRAIL receptors in MDA-MB-231 breast cancer cells. Int J Oncol 2013;43:121-30.

151. Hayward P, Kalmar T, Arias AM. Wnt/Notch signalling and information processing during development. Development 2008;135:411-24.

152. Couso JP, Martinez Arias A. Notch is required for wingless signalling in the epidermis of Drosophila. Cell 1994;79:259-72.

153. Brennan K, Klein T, Wilder E, et al. Wingless modulates the effects of dominant negative notch molecules in the developing wing of Drosophila. Dev Biol 1999;216:210-29.

154. Hayward P, Brennan K, Sanders P, et al. Notch modulates Wnt signalling by associating with Armadillo/beta-catenin and regulating its transcriptional activity. Development 2005;132:1819-30.
155. Kwon C, Cheng P, King IN, et al. Notch post-translationally regulates beta-catenin protein in stem and progenitor cells. Nat Cell Biol 2011;13:1244-51.

156. Acosta H, Lopez SL, Revinski DR, et al. Notch destabilises maternal beta-catenin and restricts dorsal-anterior development in Xenopus. Development 2011;138:2567-79.

157. Sanders PG, Munoz-Descalzo S, Balayo T, et al. Ligand-independent traffic of Notch buffers activated Armadillo in Drosophila. PLoS Biol 2009;7:e1000169.

158. van Noort M, Weerkamp F, Clevers HC, et al. Wnt signalling and phosphorylation status of beta-catenin: Importance of the correct antibody tools. Blood 2007;110:2778-9.

159. Kwon C, Qian L, Cheng P, et al. A regulatory pathway involving Notch1/beta-catenin/Isl1 determines cardiac progenitor cell fate. Nat Cell Biol 2009;11:951-7.

160. Tamura K, Taniguchi Y, Minoguchi S, et al. Physical interaction between a novel domain of the receptor Notch and the transcription factor RBP-J kappa/Su(H). Curr Biol 1995;5:1416-23.

161. Logan CY, Nusse R. The Wnt signalling pathway in development and disease. Annu Rev Cell Dev Biol 2004;20:781-810.

162. Winston JT, Strack P, Beer-Romero P, et al. The SCFbeta-TRCPubiquitin ligase complex associates specifically with phosphorylated destruction motifs in IkappaBalpha and beta-catenin and stimulates IkappaBalpha ubiquitination in vitro. Genes Dev 1999;13:270-83.

163. Muñoz-Descalzo S, Tkocz K, Balayo T, Arias AM. Modulation of the ligand-independent traffic of Notch by Axin and Apc contributes to the activation of Armadillo in Drosophila. Development 2011;13:1501-6. 


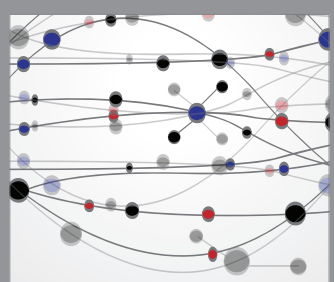

The Scientific World Journal
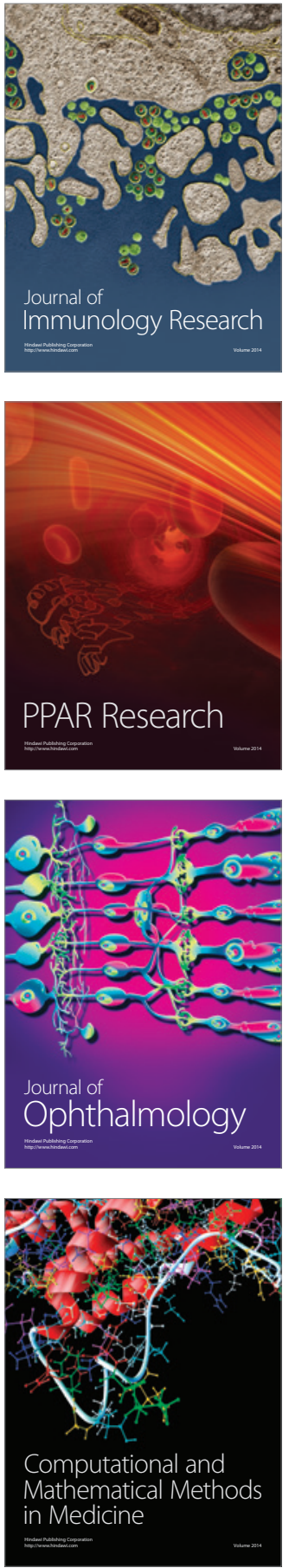

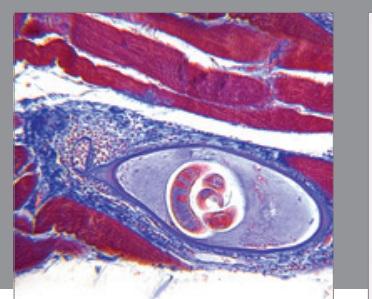

Gastroenterology Research and Practice

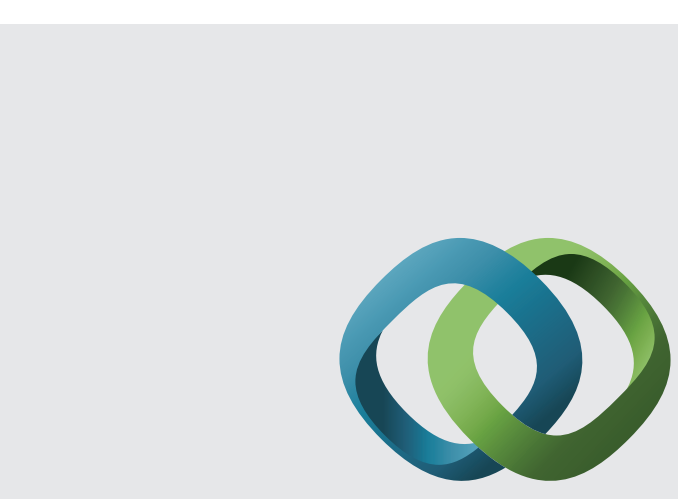

\section{Hindawi}

Submit your manuscripts at

http://www.hindawi.com
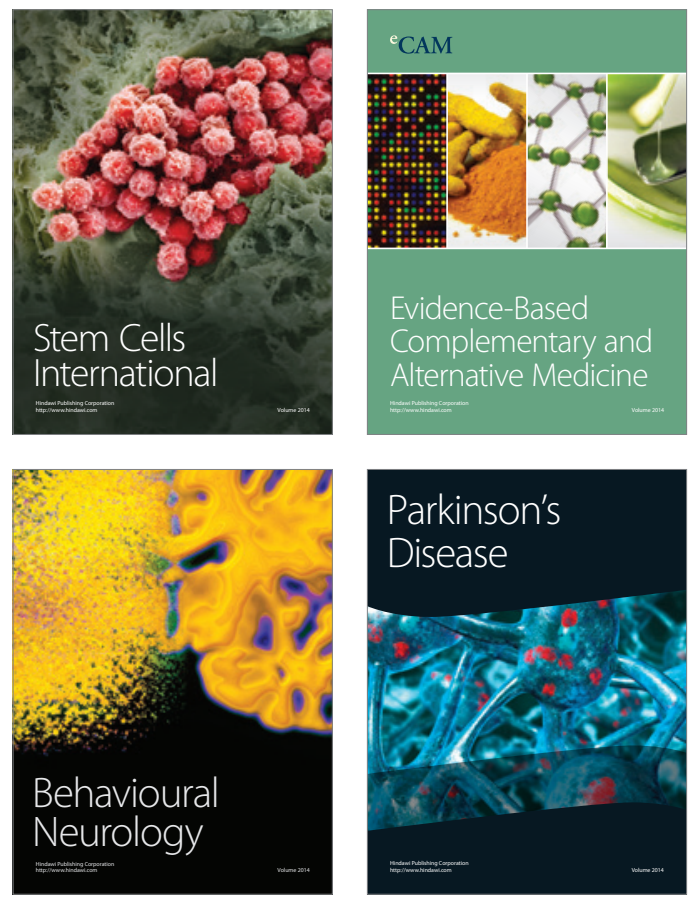
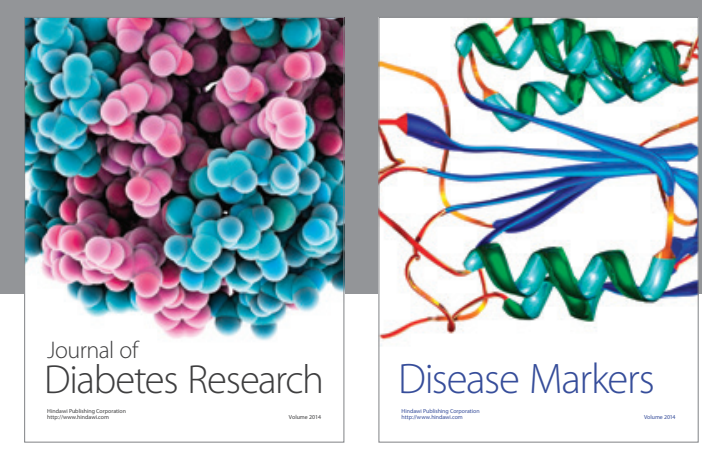

Disease Markers
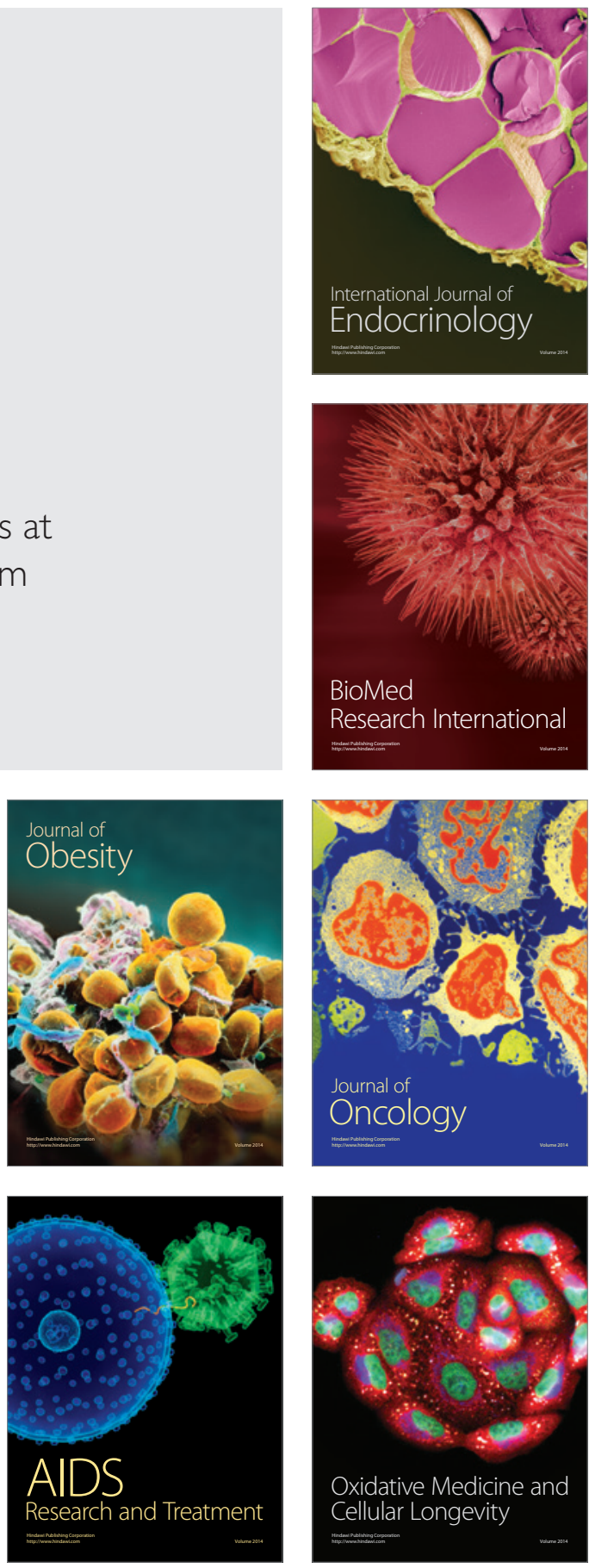